\title{
Nuclear data impact on multiplication factor and reactor physics parameters calculation for experiments simulating damp MOX powders
}

\author{
T. Ivanova ${ }^{a}$, I. Duhamel, S. Evo, and E. Létang \\ Institut de Radioprotection et de Sûreté Nucléaire, BP. 17, 92262 Fontenay-aux-Roses, France
}

\begin{abstract}
The paper presents calculation results for experiments performed to address needs of the MOX fuel manufacturing process and particularly with low-moderated MOX fissile media. Computation of criticality for eleven configurations and reaction rates ratios for major and minor actinides are performed with CRISTAL french criticality code package, and the reference MCNPX and TRIPOLI-4.3 codes. The multigroup JEF-2.2, JEFF-3.1 and continuous energy JEF-2.2, JEFF-3.1, ENDF/B-VI and ENDF/B-VII neutron cross sections are used for the computations. The results are compared to verify group-wise calculations. Then the obtained calculated values will be used to predict eigenvalue accuracy for applications with damp MOX powder, and to validate ${ }^{238} \mathrm{U},{ }^{239} \mathrm{Pu}$, and ${ }^{240} \mathrm{Pu}$ cross sections.
\end{abstract}

\section{Introduction}

The experimental program was specifically performed to obtain additional integral benchmark data for the MOX fuel manufacturing process and particularly with low-moderated MOX fissile media[1, 2]. A series of critical configurations was performed at the Institute of Physics and Power Engineering (IPPE), Obninsk, Russia at the BFS-1 critical facility.

The detailed benchmark specifications have been issued for the eleven configurations and published in the ICSBEP and IRPhEP Handbooks [3, 4].

The main goal of this work was the computational analysis of the experiments with the CRISTAL criticality package [5], verification of the CRISTAL results by comparison with the reference MCNPX [6] and TRIPOLI-4.3 [7] codes. The totality of the results, then, will be involved in the "adjustment" procedure in order to 1) predict $\mathrm{k}_{\text {eff }}$ bias and its uncertainty for applications with damp MOX powder, and 2) validate ${ }^{238} \mathrm{U}$, ${ }^{239} \mathrm{Pu}$, and ${ }^{240} \mathrm{Pu}$ cross sections.

\section{Description of the experiments}

In the experiments damp MOX powders were simulated by assembling tightly packed cylindrical aluminium tubes containing various ratios of metallic plutonium and depleted uranium dioxide fuel pellets. The tubes with outer diameter of $5.0 \mathrm{~cm}$ and $0.1 \mathrm{~cm}$ wall thickness and $5.1 \mathrm{~cm}$ hexagonal pitch were put inside a cylindrical steel vessel with $200.2 \mathrm{~cm}$ inner diameter, and $277.5 \mathrm{~cm}$ height.

The specified water content was achieved by periodically including polyethylene dowels and/or polyethylene pellets. The composition of fuel material was investigated with two types of plutonium with different content of ${ }^{240} \mathrm{Pu}$. Axial and radial reflectors were depleted uranium dioxide.

Principal characteristics of the experiments are shown in table 1.

\footnotetext{
${ }^{a}$ Presenting author, e-mail: tatiana.ivanova@irsn.fr
}

Table 1. Principal characteristics of the BFS assemblies.

\begin{tabular}{cccccc}
\hline BFS & $\begin{array}{c}\text { Neutron } \\
\text { Spectrum }\end{array}$ & $\begin{array}{c}\mathrm{Pu} \\
\text { Content, } \\
\text { wt. } \%\end{array}$ & $\begin{array}{c}{ }^{240} \mathrm{Pu} \\
\text { Content, } \\
\text { wt.\% }\end{array}$ & $\mathrm{H} / \mathrm{Pu}$ & $\begin{array}{c}\text { Equiv. } \\
\text { Water } \\
\text { Content, } \\
\text { wt.\% }\end{array}$ \\
\hline $97 / 1$ & Fast & 22 & 4.6 & 0.0 & 0.0 \\
\hline $97 / 2$ & Fast & 22 & 4.6 & 1.0 & 0.6 \\
\hline $97 / 3$ & Mixed & 22 & 4.6 & 4.7 & 2.5 \\
\hline $97 / 4$ & Mixed & 22 & 4.6 & 6.0 & 3.4 \\
\hline $99 / 1$ & Mixed & 22 & 10.1 & 4.7 & 2.5 \\
\hline $99 / 1 \mathrm{~A}$ & Mixed & 22 & 10.1 & 4.7 & 2.5 \\
\hline $99 / 2$ & Mixed & 22 & 10.1 & 6.0 & 3.4 \\
\hline $101 / 1$ & Fast & 10 & 4.6 & 2.5 & 0.7 \\
\hline $101 / 2$ & Mixed & 10 & 4.6 & 4.7 & 1.3 \\
\hline $101 / 2 \mathrm{~A}$ & Mixed & 10 & $4.6 / 10.1^{*}$ & $4.7 / 7.4$ & $1.3 / 2.1$ \\
\hline $101 / 3$ & Mixed & 10 & 4.6 & 7.5 & 2.1 \\
\hline
\end{tabular}

* Different characteristics shown relate to inner and outer core tubes.

The following measurements performed on the assemblies are analysed in the paper:

- criticality;

- spectral indices;

- central reaction rate ratios measured on the BFS-97/1, $-97 / 3,-99 / 1$, and $-101 / 2$ assemblies.

A triple-segment fission chamber with fissile deposits of ${ }^{235} \mathrm{U}$, ${ }^{238} \mathrm{U}$, and ${ }^{239} \mathrm{Pu}$ was used for simultaneous measurements of ${ }^{235} \mathrm{U},{ }^{238} \mathrm{U}$, and ${ }^{239} \mathrm{Pu}$ fission rates. Measurements at the core center were performed in the empty channel formed by extraction of the central fuel tube.

Ratios of minor actinides $\left({ }^{237} \mathrm{~Np},{ }^{241} \mathrm{Am},{ }^{243} \mathrm{Am},{ }^{244} \mathrm{Cm}\right.$, and $\left.{ }^{245} \mathrm{Cm}\right)$ to ${ }^{239} \mathrm{Pu}$ fission rates $\left(\mathrm{F}^{M A} / \mathrm{F}^{\text {Pu239 }}\right)$ were also measured by absolute fission chambers in the center of the core.

The ${ }^{238} \mathrm{U}$ capture rate to ${ }^{235} \mathrm{U}$ fission rate ratio $\left(\mathrm{C}^{\mathrm{U} 238} / \mathrm{F}^{\mathrm{U} 235}\right)$ was measured by activation method. Small square or round foils, placed in the central cell of the assembly either between two hemi cylindrical halves of a dismountable depleted uranium dioxide pellet or between two vertically adjacent depleted uranium dioxide pellets, were used for activation. 


\section{Modelling of the experiments}

\subsection{Criticality}

The CRISTAL general-purpose criticality analysis package has been used to compute $\mathrm{k}_{\mathrm{eff}}$ values for all the configurations. Its standard route is based on JEF-2.2 [8] nuclear data and comprises the following tools:

- APOLLO2 [9] for lattice calculation using multigroup non adjusted cross-section library, and

- MORET 4 code [10] for 3D calculation of neutron transport with Monte Carlo method.

The following approximations are adopted in the APOLLO2 code used for this study:

- 172-energy group structure;

- Anisotropy: $\mathrm{P}_{5}$ for $\mathrm{U}, \mathrm{Pu},{ }^{241} \mathrm{Am}$ and $\mathrm{CH}_{2} ; \mathrm{P}_{1}$ for other nuclides;

- Resonance self-shielding using infinite dilution cross section approach;

- Flux calculation with the collision probability method;

- Use of equivalent theorem for macroscopic cross section preparation.

The JEFF-3.1 library [11] was also used with APOLLO2MORET 4 route.

Since the calculation of the experiments addressing MOX issue was a first attempt to analyse the critical configurations assembled on the BFS facility, an effect of one-dimensional heterogeneous cell model on the analysis's accuracy was estimated and the $\mathrm{k}_{\mathrm{eff}}$ results are verified by comparison with the reference TRIPOLI-4.3 and MCNPX codes.

The JEF-2.2, JEFF-3.1, ENDF/B-VI.6 and ENDF/B-VII [12] continuous energy neutron data were used with MCNPX.

The APOLLO2-MORET 4 calculation models are the following: set of infinite plates for lattice computations and detailed description of the core tubes in the MORET 4 inputs. Reflector is presented as homogeneous.

The detailed models of the configurations are created for calculations with references tools.

\subsection{Reaction rate ratios}

To obtain spectral indices an average neutron energydependent flux in the volume of interest was computed and multiplied by the specific cross section as follows: $R_{x}=\int \bar{\phi}_{V}(E) \sigma_{R}^{x}(E) d E$, where $\bar{\phi}_{V}$ is the neutron flux averaged on the volume of interest; $\sigma_{R}^{x}$ is the microscopic cross section of reaction $\mathrm{R}$ corresponding to isotope $x$.

Calculations of these rates are performed using the track length estimate of cell flux tally (F4) with the MCNPX. Variance reduction methods are used to compute capture rate for ${ }^{238} \mathrm{U}$.

The fission rates are calculated with the APOLLO2MORET 4 route as follows:

$$
R_{x}=\sum_{g=1}^{172} \bar{\phi}_{V}^{g} \sigma_{R x}^{g},
$$

where $\bar{\phi}_{V}^{g}$ is volume-averaged neutron flux estimated on neutron track length, and $\sigma_{R x}^{g}$ is the microscopic cross sections in group $g$ of reaction $R$ corresponding to isotope $x$, tabulated in multigroup library (without taking into account resonance self-shielding calculation). All the values obtained in such a way are verified by comparison with the MCNPX results. The ${ }^{238} \mathrm{U}$ capture rates are not computed.

The computation of the reaction rate ratios is performed as follows: $R=R_{x} / R_{y}$, where $R_{x}$ and $R_{y}$ are spectral indices of interest, calculated with the MCNPX or APOLLO2-MORET 4 codes.

The dispersions associated with the mentioned reaction rate ratios are calculated as follows:

$$
\Delta\left(\frac{R_{x}}{R_{y}}\right)=\sqrt{\left(\frac{\Delta R_{x}}{R_{y}}\right)^{2}+\left(\frac{R_{x} \Delta R_{y}}{R_{y}^{2}}\right)^{2}} .
$$

\section{Results}

The results of the above described criticality and reaction rate ratios calculations are presented in the figures and the tables in this paragraph. The quoted statistical uncertainties are given as single standard deviation.

\subsection{Criticality}

Table 2. Comparison of JEF-2.2 and JEFF- $3.1 \mathrm{k}_{\text {eff }}$ results computed with APOLLO2-MORET 4 and MCNPX codes.

\begin{tabular}{ccccc}
\hline & & ${ }^{240} \mathrm{Pu}$ & & \multicolumn{2}{l}{$\mathrm{C}^{\mathrm{JEF}-2.2} / \mathrm{C}^{\mathrm{JEFF}-3.1}-1, \%$} \\
\cline { 4 - 5 } $\mathrm{BFS}$ & $\mathrm{H} / \mathrm{Pu}$ & $\begin{array}{c}\text { Content, } \\
\text { wt.\% }\end{array}$ & $\begin{array}{c}\text { APOLLO2 } \\
\text { APORET 4 }\end{array}$ & MCNPX \\
\hline & & & /MOR & \\
\hline $97 / 1$ & 0 & 4.6 & $-0.47 \pm 0.04$ & $-0.08 \pm 0.03$ \\
$97 / 2$ & 1.1 & 4.6 & $-0.49 \pm 0.04$ & $-0.07 \pm 0.03$ \\
$97 / 3$ & 4.7 & 4.6 & $-0.61 \pm 0.04$ & $-0.32 \pm 0.03$ \\
$97 / 4$ & 6 & 4.6 & - & $-0.33 \pm 0.03$ \\
\hline $99 / 1$ & 4.6 & 10.1 & $-0.72 \pm 0.04$ & $-0.44 \pm 0.03$ \\
$99 / 1 \mathrm{~A}$ & 4.6 & 10.1 & $-0.79 \pm 0.04$ & $-0.48 \pm 0.03$ \\
$99 / 2$ & 5.9 & 10.1 & $-0.74 \pm 0.04$ & $-0.36 \pm 0.03$ \\
\hline $101 / 1$ & 2.4 & 4.6 & $-0.65 \pm 0.04$ & $-0.04 \pm 0.03$ \\
$101 / 2$ & 4.7 & 4.6 & $-0.38 \pm 0.04$ & $-0.15 \pm 0.03$ \\
$101 / 2 \mathrm{~A}$ & 4.7 & $4.6 / 10.1$ & $-0.59 \pm 0.04$ & $-0.20 \pm 0.03$ \\
$101 / 3$ & 7.4 & 4.6 & $-0.47 \pm 0.04$ & $-0.30 \pm 0.03$ \\
\hline
\end{tabular}

Table 3. $\mathrm{k}_{\mathrm{eff}}$ values computed with MCNPX code, C/E-1 (\%).

\begin{tabular}{cccccc}
\hline & \multicolumn{5}{c}{ ENDF/B- ENDF/B- } \\
BFS & JEF-2.2 & JEFF-3.1 & VI.6 & VII & Unc., \% \\
\hline $97 / 1$ & -0.71 & -0.64 & -0.10 & -0.71 & 0.29 \\
$97 / 2$ & -0.47 & -0.40 & 0.03 & -0.22 & 0.26 \\
$97 / 3$ & -0.19 & 0.18 & 0.07 & 0.32 & 0.31 \\
$97 / 4$ & -0.33 & 0.04 & -0.10 & 0.16 & 0.27 \\
\hline $99 / 1$ & 0.57 & 1.06 & 1.12 & 1.19 & 0.28 \\
$99 / 1 \mathrm{~A}$ & 0.45 & 0.93 & 0.90 & 1.00 & 0.28 \\
$99 / 2$ & 0.54 & 0.92 & 0.95 & 1.08 & 0.26 \\
\hline $101 / 1$ & -0.91 & -0.86 & 0.00 & -0.57 & 0.22 \\
$101 / 2$ & -0.69 & -0.43 & 0.04 & -0.23 & 0.21 \\
$101 / 2 \mathrm{~A}$ & -0.38 & -0.15 & 0.37 & 0.09 & 0.20 \\
$101 / 3$ & -0.81 & -0.42 & -0.31 & -0.36 & 0.21 \\
\hline
\end{tabular}




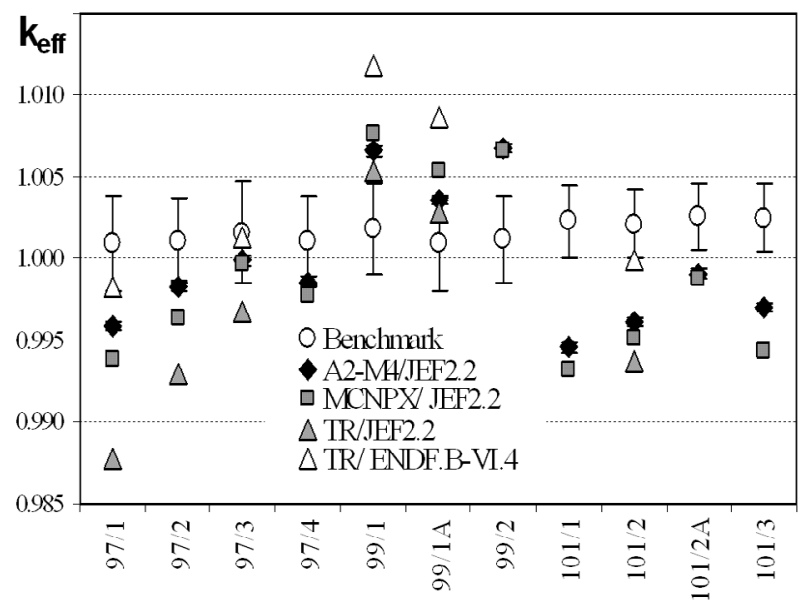

Fig. 1. Results of $\mathrm{k}_{\mathrm{eff}}$ computations with APOLLO2-MORET 4 (A2M4), TRIPOLI-4.3 (TR), and MCNPX codes.

\subsection{Reaction rate ratios}

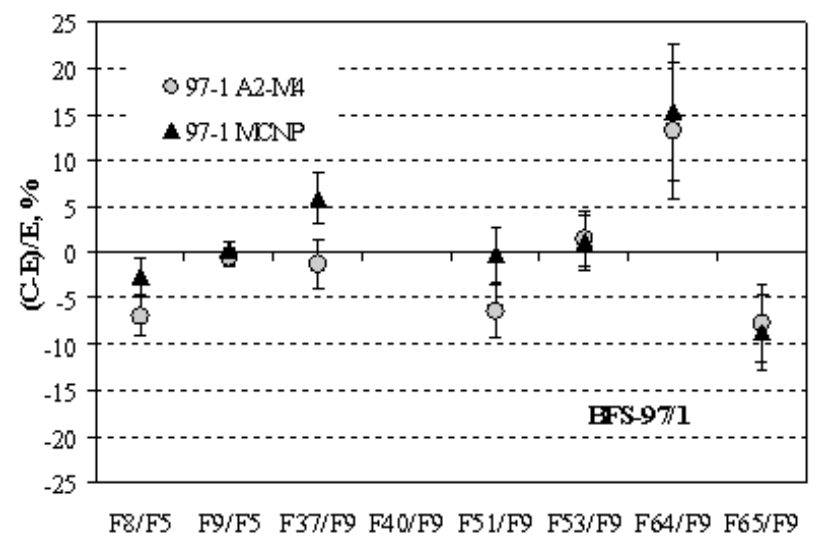

Fig. 2. Comparison of JEF-2.2 fission reaction rate ratios results computed with APOLLLO2-MORET 4 (A2-M4) and MCNPX codes for the BFS-97/1 assembly.

\section{Conclusions}

The calculated $\mathrm{k}_{\mathrm{eff}}$ values tend to be lower than the benchmark values for configurations with weapons-grade $\mathrm{Pu}$ for all the libraries except ENDF/B-VI.6, and substantially higher for reactor-grade $\mathrm{Pu}$, irrespective of the library used (see table 3, and fig. 1). Sensitivity study shows that this overestimate may hardly be due to error of ${ }^{240} \mathrm{Pu}$ content in $\mathrm{Pu}$ pellets (isotopic composition of $\mathrm{Pu}$ pellets corresponds to those indicated in passport data but was not measured).

Table 3 depicts that all the libraries produce good agreement for "small" configurations (BFS-97) with relatively high equivalent water content ( $>2$ wt. $\%$ ).

The JEFF-3.1 $\mathrm{k}_{\mathrm{eff}}$ results are systematically superior to the JEF-2.2 results (see tables 2 and 3).
Table 4. Minor actinides to ${ }^{239} \mathrm{Pu}$ fission rates computed with $\mathrm{MC}$ NPX, C/E-1 (\%).

\begin{tabular}{|c|c|c|c|}
\hline & JEF-2.2 & JEFF-3.1 & ENDF/B-VII \\
\hline \multicolumn{4}{|c|}{ BFS-97/1 } \\
\hline $\mathrm{F}^{\mathrm{Np} 237} / \mathrm{F}^{\mathrm{Pu} 239}$ & $0.3 \pm 2.7$ & $5.9 \pm 2.7$ & $5.0 \pm 2.7$ \\
\hline $\mathrm{F}^{\mathrm{Am} 241} / \mathrm{F}^{\mathrm{Pu} 239}$ & $-3.3 \pm 2.9$ & $-0.3 \pm 3.0$ & $-0.7 \pm 3.0$ \\
\hline $\mathrm{F}^{\mathrm{Am} 243} / \mathrm{F}^{\mathrm{Pu} 239}$ & $5.25 \pm 3.0$ & $1.1 \pm 3.0$ & $1.1 \pm 3.0$ \\
\hline $\mathrm{F}^{\mathrm{Cm} 244} / \mathrm{F}^{\mathrm{Pu} 239}$ & $15.0 \pm 7.4$ & $15.3 \pm 7.4$ & $13.2 \pm 7.4$ \\
\hline $\mathrm{F}^{\mathrm{Cm} 245} / \mathrm{F}^{\mathrm{Pu} 239}$ & $-9.2 \pm 4.2$ & $-8.7 \pm 4.2$ & $-8.4 \pm 4.2$ \\
\hline \multicolumn{4}{|c|}{ BFS-97/3 } \\
\hline $\mathrm{F}^{\mathrm{Np} 237} / \mathrm{F}^{\mathrm{Pu} 239}$ & $-2.6 \pm 3.0$ & $1.3 \pm 2.9$ & $1.9 \pm 2.9$ \\
\hline $\mathrm{F}^{\mathrm{Am} 241} / \mathrm{F}^{\mathrm{Pu} 239}$ & $-5.3 \pm 3.3$ & $-2.2 \pm 3.2$ & $-6.4 \pm 3.2$ \\
\hline $\mathrm{F}^{\mathrm{Am} 243} / \mathrm{F}^{\mathrm{Pu} 239}$ & $-3.4 \pm 3.8$ & $-5.3 \pm 3.7$ & $-4.5 \pm 3.7$ \\
\hline $\mathrm{F}^{\mathrm{Cm} 244} / \mathrm{F}^{\mathrm{Pu} 239}$ & $43.9 \pm 2.0$ & $38.7 \pm 1.5$ & $32.3 \pm 1.5$ \\
\hline $\mathrm{F}^{\mathrm{Cm} 245} / \mathrm{F}^{\mathrm{Pu} 239}$ & $-4.0 \pm 5.1$ & $1.5 \pm 5.0$ & $3.7 \pm 5.0$ \\
\hline \multicolumn{4}{|c|}{ BFS-99/1 } \\
\hline $\mathrm{F}^{\mathrm{Np} 237} / \mathrm{F}^{\mathrm{Pu} 239}$ & $-5.3 \pm 3.0$ & $1.9 \pm 3.3$ & $4.3 \pm 3.2$ \\
\hline $\mathrm{F}^{\mathrm{Pu} 240} / \mathrm{F}^{\mathrm{PU} 239}$ & $3.4 \pm 3.2$ & $-0.1 \pm 3.5$ & $6.0 \pm 3.4$ \\
\hline $\mathrm{F}^{\mathrm{Am} 241} / \mathrm{F}^{\mathrm{Pu} 239}$ & $-7.7 \pm 3.3$ & $0.6 \pm 3.4$ & $-1.5 \pm 3.5$ \\
\hline $\mathrm{F}^{\mathrm{Am} 243} / \mathrm{F}^{\mathrm{Pu} 239}$ & $-6.0 \pm 3.8$ & $-7.1 \pm 4.1$ & $-4.4 \pm 4.0$ \\
\hline \multicolumn{4}{|c|}{ BFS-101/2 } \\
\hline $\mathrm{F}^{\mathrm{Np} 237} / \mathrm{F}^{\mathrm{Pu} 239}$ & $-5.1 \pm 3.8$ & $-2.6 \pm 3.2$ & $-1.6 \pm 3.2$ \\
\hline $\mathrm{F}^{\mathrm{Pu} 240} / \mathrm{F}^{\mathrm{PU} 239}$ & $6.8 \pm 3.9$ & $-1.4 \pm 3.3$ & $0.1 \pm 3.3$ \\
\hline $\mathrm{F}^{\mathrm{Am} 241} / \mathrm{F}^{\mathrm{Pu} 239}$ & $-2.1 \pm 4.0$ & $-0.5 \pm 3.5$ & $-5.4 \pm 3.5$ \\
\hline $\mathrm{F}^{\mathrm{Am} 243} / \mathrm{F}^{\mathrm{Pu} 239}$ & $-9.7 \pm 3.6$ & $-13.9 \pm 3.1$ & $-11.8 \pm 3.1$ \\
\hline
\end{tabular}

Table 5. ${ }^{238} \mathrm{U}$ and ${ }^{239} \mathrm{Pu}$ fission to ${ }^{235} \mathrm{U}$ fission rate computed with MCNPX, C/E-1 (\%).

\begin{tabular}{|c|c|c|c|}
\hline & JEF-2.2 & JEFF-3.1 & ENDF/B-VII \\
\hline \multicolumn{4}{|c|}{ BFS-97/1 } \\
\hline $\mathrm{FU}^{2} 38 / \mathrm{F}^{\mathrm{O} 235}$ & $0.6 \pm 2.0$ & $-2.6 \pm 2.0$ & $-2.0 \pm 2.0$ \\
\hline $\mathrm{F}^{\mathrm{Pu} 239} / \mathrm{F}^{\mathrm{U} 235}$ & $1.3 \pm 1.0$ & $0.2 \pm 1.0$ & $0.0 \pm 1.0$ \\
\hline \multicolumn{4}{|c|}{ BFS-97/3 } \\
\hline $\mathrm{F}^{\mathrm{U} 238} / \mathrm{F}^{\mathrm{U} 235}$ & $-4.1 \pm 2.5$ & $-4.8 \pm 2.5$ & $-7.5 \pm 2.5$ \\
\hline $\mathrm{F}^{\mathrm{Pu} 239} / \mathrm{F}^{\mathrm{U} 235}$ & $-3.6 \pm 2.3$ & $-1.3 \pm 2.1$ & $-6.4 \pm 2.2$ \\
\hline
\end{tabular}

Table 6. ${ }^{238} \mathrm{U}$ capture rate to ${ }^{235} \mathrm{U}$ fission rate computed with MCNPX/JEF-2.2, C/E-1 (\%).

\begin{tabular}{cccc}
\hline Foil Position $\rightarrow$ & 1 & 2 & 3 \\
\hline BFS-97/1 & $3.7 \pm 2.7$ & $7.1 \pm 3.3$ & - \\
BFS-97/3 & $7.0 \pm 3.3$ & $9.7 \pm 3.2$ & $8.5 \pm 2.7$ \\
\hline BFS-99/1 & $7.1 \pm 5.0$ & $10.2 \pm 4.3$ & $7.3 \pm 2.9$ \\
\hline BFS-101/2 & $0.4 \pm 2.8$ & $0.2 \pm 3.5$ & $2.0 \pm 4.1$ \\
\hline
\end{tabular}

Overall, ENDF/B-VI.6 produces better agreement with $\mathrm{k}_{\mathrm{eff}}$ benchmark values than other libraries do for 8 configurations with weapons-grade $\mathrm{Pu}$ : majority of the ENDF/B-VI.6 results are within one standard deviations of the corresponding benchmark value, but only 3 ENDF/B-VII and JEFF-3.1 results, and $1 \mathrm{JEF}-2.2$ result are (see table 3 ). 
The JEFF-3.1 and ENDF/B-VII libraries recently released produce big spread of the $\mathrm{k}_{\text {eff }}$ results (about $1.9 \%$ ) for totality of the BFS configurations, while JEF-2.2 and ENDF/B-VI.6 libraries do $1.5 \%$ (see table 3 ).

Comparison of the multigroup APOLLO2-MORET 4 and continuous energy MCNPX results based on the same evaluated nuclear data files, are in a good agreement for both criticality and reaction rates computation with JEF-2.2 for all the configurations and for majority of the cases calculated with JEFF-3.1 (see table 2 and fig. 2). Discrepancy observed for $\mathrm{k}_{\text {eff }}$ obtained with JEFF-3.1 (see table 2) for configurations with fast neutron spectrum requires analysis of both point- and group-wise cross section preparation.

Most of the results for the fission reaction-rate calculations are within the evaluated uncertainty of the experimental values and statistical uncertainty of computations (see tables 4 and 5).

$\mathrm{F}^{\mathrm{Cm} 244} / \mathrm{F}^{\mathrm{Pu} 239}$ ratios are significantly superior (up to $44 \%$ ) to the measured values for all the libraries used (see table 4).

Systematic overestimation of the $\mathrm{C}^{U 238} / \mathrm{F}^{U 235}$ ratio is discovered for "small" configurations computation based on JEF2.2 library (see table 6).

\section{References}

1. The Need for Integral Critical Experiments with Low-moderated MOX Fuels, in Proceedings of the Workshop, Paris, France, 1415 April 2004, OECD NEA, No. 5668, ISBN 92-64-02078-0.

2. Report on Ad-hoc Expert Group of the NEA Working Party on Nuclear Criticality Safety (ISBN 92-64-01049-1, NEA No. 6047, OECD 2005).
3. International Handbook of Evaluated Criticality Safety Benchmark Experiments, OECD-NEA, NEA/NSC DOC(95)03, September 2006 Edition.

4. International Handbook of Evaluated Reactor Physics Benchmark Experiments, NEA/NSC/DOC(2006)1, March 2007 Edition.

5. J.-M. Gomit et al., CRISTAL V1: Criticality Package for Burnup Credit Calculation, in Proceedings of the Meeting Integrating Criticality Safety into the Resurgence of Nuclear Power, Knoxville, Tennessee, Sept. 19-22, 2005, on CD-ROM, ANS, LaGrange Park, IL (2005).

6. RSICC Computer Code Collection, Monte Carlo N-Particle Transport Code System CCC-730/ MCNP/MCNPX code package.

7. J.-P. Both et al., TRIPOLI-4 - A Three Dimensional Polykinetic Particle Transport Monte Carlo Code, Proceedings of the International Meeting SNA'2003, Paris, 2003.

8. JEF Report 17, The JEF-2.2 Nuclear Data Library, OECD-NEA, 2000.

9. S. Loubière et al., APOLLO2 Twelve Years Later, Proceedings of the International conference on Mathematics And Computation, Reactor Physics And Environmental Analysis In Nuclear Applications, Madrid, Spain, 1999, Vol. 2, p. 1298.

10. O. Jacquet et al., MORET: Version 4.B, a Multigroup Monte Carlo Criticality Code Package, Proceedings of the International Meeting on Nuclear Criticality Safety, Tokai Mura, Japan, 2003.

11. J.-C. Sublet, MCNP4c JEFF3.1 based libraries, Rapport CEAR-6110, 2006.

12. M.B. Chadwick, P. Oblozinsky et al. (CSEWG collaboration), ENDF/B-VII: Next Generation Evaluated Nuclear Data Library for Nuclear Science and Technology, Nucl. Data Sheets 107, 2931 (2006). 